\title{
Associations of serum insulin-like growth factor-I and insulin-like growth factor-binding protein 3 levels with biomarker-calibrated protein, dairy product and milk intake in the Women's Health Initiative
}

\author{
Jeannette M. Beasley*, Marc J. Gunter, Andrea Z. LaCroix, Ross L. Prentice, Marian L. Neuhouser, \\ Lesley F. Tinker, Mara Z. Vitolins and Howard D. Strickler
}

Albert Einstein College of Medicine, 1300 Morris Park Avenue, Belfer 1312c, Bronx, NY 10461, USA

(Submitted 5 September 2012 - Final revision received 28 August 2013 - Accepted 29 August 2013 - First published online 7 October 2013)

\section{Abstract}

It is well established that protein-energy malnutrition decreases serum insulin-like growth factor (IGF)-I levels, and supplementation of $30 \mathrm{~g}$ of whey protein daily has been shown to increase serum IGF-I levels by $8 \%$ after 2 years in a clinical trial. Cohort studies provide the opportunity to assess associations between dietary protein intake and IGF axis protein levels under more typical eating conditions. In the present study, we assessed the associations of circulating IGF axis protein levels (ELISA, Diagnostic Systems Laboratories) with total biomarker-calibrated protein intake, as well as with dairy product and milk intake, among postmenopausal women enrolled in the Women's Health Initiative ( $n 747)$. Analyses were carried out using multivariate linear regression models that adjusted for age, BMI, race/ethnicity, education, biomarker-calibrated energy intake, alcohol intake, smoking, physical activity and hormone therapy use. There was a positive association between milk intake and free IGF-I levels. A three-serving increase in milk intake per d (approximately $30 \mathrm{~g}$ of protein) was associated with an estimated average $18.6 \%$ higher increase in free IGF-I levels (95\% CI 0.9, 39.3\%). However, total IGF-I and insulin-like growth factor-binding protein 3 (IGFBP-3) levels were not associated with milk consumption and nor were there associations between biomarker-calibrated protein intake, biomarkercalibrated energy intake, and free IGF-I, total IGF-I or IGFBP-3 levels. The findings of the present study carried out in postmenopausal women are consistent with clinical trial data suggesting a specific relationship between milk consumption and serum IGF-I levels, although in the present study this association was only statistically significant for free, but not total, IGF-I or IGFBP-3 levels.

Key words: Insulin-like growth factor-I: Insulin-like growth factor-binding protein-3: Dairy products: Milk: Biomarker-calibrated protein intake

Recent research carried out by our group and others suggests that higher protein intake may be associated with the preservation of lean body mass ${ }^{(1)}$ and reduced frailty ${ }^{(2)}$ in postmenopausal women. The characterisation of mechanisms through which higher protein intake may be related to successful ageing phenotypes could inform dietary guidelines. The insulin-like growth factor (IGF) axis constitutes an evolutionarily conserved system involved in the regulation of cell growth, proliferation and survival that affects nearly every organ system in the body. The axis consists of two phylogenetically conserved peptide ligands, IGF-I and IGF-II, with potent anabolic effects and six high-affinity binding proteins (insulin-like growth factor-binding protein (IGFBP)-1 to IGFBP-6) ${ }^{(3)}$.

IGF-I is the primary mediator of the effects of growth hormone and is thought to be the major IGF affecting growth, health and disease following fetal development ${ }^{(4,5)}$. IGF-I shares extensive sequence homology and downstream signalling pathways with insulin and has insulin-like effects on glucose and fat uptake in peripheral tissues. However, IGF-I exhibits stronger mitogenic and anti-apoptotic activity than insulin ${ }^{(6)}$. Previous research has suggested that circulating IGF-I levels may influence the risk of cancer $^{(4)}$, diabetes ${ }^{(5)}$ and other conditions related to healthy ageing $^{(7)}$. Most of the IGF-I in the circulation is produced by the liver and is bound to IGFBP, with IGFBP-3 binding $75 \%$ or more of all IGF-I in the blood. Only approximately $1 \%$ of total serum IGF-I is unbound, and this free fraction may be the most biologically active component of total IGF-I ${ }^{(8)}$.

It is well known that diets deficient in energy and/or protein lead to substantive reductions in serum IGF-I levels ${ }^{(9)}$; however, the role of protein and other dietary factors under conditions of weight maintenance is not well characterised. Significant increases in serum IGF-I levels $(51.5$ (95\% CI $18 \cdot 6,84 \cdot 4) \%$

Abbreviations: EPIC, European Prospective Investigation into Cancer and Nutrition; IGFBP, insulin-like growth factor-binding protein; IGF, insulin-like growth factor; WHI, Women's Health Initiative; WHI-OS, Women's Health Initiative - Observational Study.

* Corresponding author: Dr J. M. Beasley, email jeannette.beasley@einstein.yu.edu 
after 6 months and $8 \%(P=0 \cdot 016)$ after 2 years, respectively) have been reported by two randomised, controlled trials of $20 \mathrm{~g}^{(10)}$ and $30 \mathrm{~g}^{(11)}$ of daily protein supplementation compared with isoenergetic placebo. A randomised trial comparing three daily servings of milk with control has reported a $10 \%$ increase in IGF-I levels $(P<0 \cdot 001)^{(12)}$. Observational studies have suggested that animal protein ${ }^{(13)}$, particularly from dairy sources $^{(14)}$, is specifically associated with higher serum IGF-I levels; such studies can help to discern whether the putative increases in IGF-I levels are sustained with habitually higher protein intake than with lower protein intake.

We are unaware of any published study that has addressed the relationship of protein intake with free IGF-I levels, and a few dietary studies have examined that with IGFBP-3 levels, though some data from two cross-sectional studies indicate that IGFBP-3 levels are not associated with protein consumption $^{(13,15)}$. The present study also has the potential advantage of having data regarding biomarker-calibrated total protein intake, thought to be a better measure of dietary intake compared with self-report alone, from the Women's Health Initiative (WHI). Therefore, the present study examined the crosssectional associations of total IGF-I, free IGF-I and IGFBP-3 levels with biomarker-calibrated total protein intake, along with uncalibrated dairy product and milk consumption, among 747 women in the WHI - Observational Study (WHI-OS) ${ }^{(16,17)}$.

\section{Methods}

\section{Study population}

The WHI-OS is a prospective cohort study that enrolled 93676 women aged 50-79 years at forty US clinical centres between 1993 and 1998, as has been described in detail elsewhere ${ }^{(18)}$. The present study was conducted according to the guidelines laid down in the Declaration of Helsinki, and all procedures involving human subjects were approved by the institutional review boards at each of the WHI clinical centres and at the Clinical Coordinating Center at the Fred Hutchinson Cancer Research Center (Seattle, Washington, USA). Written informed consent was obtained from all the participants. The participants of the present study were controls from an ancillary nested case-cohort study designed to evaluate the relationship between the IGF axis and colorectal, breast and endometrial cancers, as reported previously ${ }^{(19-21)}$. Of the 816 randomly selected controls from the WHI-OS, the analytical sample consisted of 747 women who reported plausible energy intake in FFQ (i.e. excluding values $<2510.4$ or $>20920 \mathrm{~kJ} / \mathrm{d}$ ) and having complete information on covariates needed to calculate biomarker-calibrated protein intake (age, BMI, smoking, race/ ethnicity, education, income and physical activity).

\section{Measurement of insulin-like growth factor levels}

Total IGF-I, free IGF-I and IGFBP-3 levels were determined in serum samples collected at baseline using commercially available ELISA kits (Diagnostic Systems Laboratories) ${ }^{(19-21)}$. Inter-assay $\mathrm{CV}$ were $8.2,11.2$ and $3.6 \%$ for total IGF-I, free IGF-I and IGFBP-3, respectively.

\section{Dietary protein assessment}

All the participants completed the WHI FFQ at WHI-OS baseline. The self-administered FFQ included 122 items for individual foods/food groups, nineteen adjustment items and summary questions ${ }^{(22)}$. Protein intake was characterised as absolute energy intake (total intake in grams) and relative to energy intake (as a percentage of total energy intake) and relative to body weight (as a ratio of $0 \cdot 1 \mathrm{~g}$ of daily protein intake per kg of body weight) ${ }^{(23)}$. Milk consumption was captured from FFQ questions of frequency and portion of milk as beverage, on cereals and in coffee or tea. Dairy product consumption was computed by summing milk consumption and twenty items from the FFQ querying weekly servings of cheese, yogurt and combination foods containing these items (i.e. quesadilla and cream soups).

\section{Calibrated energy and protein estimation}

As has been described previously ${ }^{(17)}$, the WHI Nutritional Biomarkers Study used objective biomarkers of total energy expenditure (equivalent to energy intake in weight-stable persons) and protein intake to assess the measurement properties of the FFQ. Briefly, 544 women from twelve clinical centres of the Dietary Modification Trial were enrolled in a doubly labelled water protocol to estimate total energy expenditure over a 2 -week period and a urinary $\mathrm{N}$ protocol to estimate protein consumption over a $24 \mathrm{~h}$ period to be compared with concurrent self-reported dietary intake data. Calibrated energy and protein estimates were obtained by introducing baseline FFQ consumption estimates and other participant characteristics obtained at baseline from the WHI-OS into linear regression calibration equations ${ }^{(19)}$. For example:

log-calibrated percentage of energy obtained from protein $=$ $2.66+0.439 \times \log$ FFQ percentage of energy obtained from protein $-0.004 \times$ BMI $-0.005 \times$ age $-0.129 \times$ current $\operatorname{smoker}(1=$ yes, $0=$ no $)$.

\section{Covariate measurements}

Data pertaining to demographic characteristics, medical history and other health-related characteristics were obtained by self-report at WHI-OS baseline. BMI was computed using measured height and weight at baseline $\left(\mathrm{kg} / \mathrm{m}^{2}\right)$.

\section{Statistical analysis}

IGF levels and protein, dairy product and milk intake were lntransformed both to better approximate a normal distribution and to allow coefficients of regression models to be interpreted as percentage difference. Spearman's correlations were calculated between the levels of total IGF-I, free IGF-I and IGFBP-3. A series of linear regression models were examined to evaluate the influence of energy intake, BMI and other potential confounders on observed associations between IGF axis component levels and protein, dairy product and milk intake. Age, energy intake and BMI were modelled as continuous variables ${ }^{(24)}$. Exposures of interest were modelled both 
Table 1. Demographic and health characteristics by free insulin-like growth factor-I tertiles ( $n$ 747), Women's Health Initiative - Observational Study (Mean values and standard deviations; number of participants and percentages)

\begin{tabular}{|c|c|c|c|c|c|c|c|c|c|}
\hline \multirow[b]{2}{*}{ Characteristics } & \multicolumn{2}{|c|}{ Overall } & \multicolumn{2}{|c|}{ Tertile 1} & \multicolumn{2}{|c|}{ Tertile 2} & \multicolumn{2}{|c|}{ Tertile 3} & \multirow[b]{2}{*}{$P$} \\
\hline & Mean & $\mathrm{SD}$ & Mean & SD & Mean & SD & Mean & $\mathrm{SD}$ & \\
\hline Age (years) & 62.9 & $7 \cdot 4$ & $62 \cdot 5$ & $7 \cdot 1$ & 63.0 & $7 \cdot 5$ & $63 \cdot 1$ & $7 \cdot 6$ & 0.34 \\
\hline $\begin{array}{l}\text { BMl }\left(\mathrm{kg} / \mathrm{m}^{2}\right) \\
\text { Ethnicity }\end{array}$ & $27 \cdot 4$ & $5 \cdot 7$ & $27 \cdot 2$ & $6 \cdot 0$ & $27 \cdot 4$ & $5 \cdot 7$ & $27 \cdot 7$ & 5.5 & $\begin{array}{l}0.37 \\
0.08\end{array}$ \\
\hline
\end{tabular}

White

n 638

Black

$n$

$\%$

Hispanic

$\%$

Other

\%

Education $\leq$ High school

Hormone therapy use

Physical activity (MET-h/week)

Dietary intake

Total energy, biomarker calibrated $(\mathrm{kJ} / \mathrm{d})$

Protein, biomarker calibrated (\% energy/d)

Protein, biomarker calibrated (g/d)

29

158

22

360

49

401

$\begin{array}{ccc}13.9 & 14.6 & 13.8 \\ & & \\ 8657 & 858 & 8661 \\ 14.3 & 1.4 & 14.2 \\ 76.3 & 11.3 & 76.7\end{array}$

33

$15 \cdot 2$

$12 \cdot 7^{33} 12 \cdot 6$

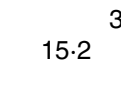

34

\begin{tabular}{rrrrrr}
100 & 8632 & \multicolumn{1}{c}{812} & 8657 & \multicolumn{1}{c}{837} & 0.96 \\
1.3 & 14.3 & 1.4 & 14.3 & 1.5 & 0.42 \\
11.3 & 76.2 & 11.2 & 75.8 & 11.4 & 0.40
\end{tabular}


Table 1. Continued

\begin{tabular}{|c|c|c|c|c|c|c|c|c|c|}
\hline \multirow[b]{2}{*}{ Characteristics } & \multicolumn{2}{|c|}{ Overall } & \multicolumn{2}{|c|}{ Tertile 1} & \multicolumn{2}{|c|}{ Tertile 2} & \multicolumn{2}{|c|}{ Tertile 3} & \multirow[b]{2}{*}{$P$} \\
\hline & Mean & SD & Mean & SD & Mean & SD & Mean & SD & \\
\hline $\begin{array}{l}\text { Protein, biomarker calibrated } \\
\text { (g/kg body weight per } \mathrm{d})\end{array}$ & 1.09 & 0.20 & $1 \cdot 11$ & $0 \cdot 19$ & 1.09 & 0.21 & 1.07 & 0.20 & 0.04 \\
\hline Dietary Ca (diet alone) $(\mathrm{mg} / \mathrm{d})$ & 847 & 461 & 842 & 445 & 841 & 436 & 859 & 501 & 0.68 \\
\hline Dietary Ca (with supplements) (mg/d) & 1264 & 815 & 1303 & 917 & 1234 & 760 & 1255 & 762 & 0.51 \\
\hline Dairy products (servings/d) & 1.9 & 1.4 & 1.9 & 1.3 & 1.9 & $1 \cdot 3$ & 1.9 & 1.5 & 0.53 \\
\hline Milk (servings/d) & 0.83 & 0.98 & 0.80 & 0.92 & 0.79 & 0.93 & 0.88 & 1.08 & 0.35 \\
\hline
\end{tabular}

MET, metabolic equivalent; \% energy, percentage of total energy intake.

continuously and categorically. Standard errors for regression coefficients where total protein was the exposure variable were estimated using a bootstrapping procedure (1000 replicates) to acknowledge the uncertainty in the regression calibration coefficients as well as that due to the sampling from the study population. To compare results with those of intervention studies, for the dairy product and milk intake analyses, both the outcome and exposure variables were log-transformed and scaled to express associations in terms of percent difference in the outcome per three-serving increase in the exposure. Logistic regression models were used to measure associations between calibrated protein intake categorised into quartiles and the odds of high serum total IGF-I, free IGF-I and IGFBP-3 levels (defined as top $10 \%)$. Additional analyses were carried out modelling the percentage of energy obtained from protein sources (animal, vegetable and milk) as the exposure variable, adjusting for $\mathrm{Ca}$ intake, restricted to participants with no history of hormone therapy use and without prevalent diabetes ( $n$ 201). Analyses stratified by BMI category $(<25,25-29 \cdot 9$ and $\geq 30 \mathrm{~kg} / \mathrm{m}^{2}$ ), protein source (animal/vegetable) and milk fat content (whole/2\%, 1\% and skimmed) were also carried out, and the $P$ for interaction term was estimated by multiplying the exposure variable by the interaction term. All analyses were carried out using SAS version 9.3 (SAS Institute)

\section{Results}

The majority of the women were White (85\%), completed at least high school education (79\%), were current users of postmenopausal hormone therapy at baseline (49\%) and were overweight (BMI 27.4 (SD 5.7) kg/m²) (Table 1). Women who were current hormone therapy users had lower free IGF-I levels $(P<0 \cdot 05)$, as reported previously ${ }^{(19-21)}$. Each of the IGF axis proteins was positively correlated with one another, with the strongest association between total IGF-I and IGFBP-3 ( $r 0.46$ and $P<0.05)$ (Table 2).

Mean calibrated protein intake was 1.1 (SD 0.2$) \mathrm{g} / \mathrm{kg}$ body weight per $\mathrm{d}$, exceeding the current RDA for protein $(0.8 \mathrm{~g} / \mathrm{kg} \text { body weight per } \mathrm{d})^{(23)}$. Expressed as a percentage of biomarker-calibrated energy intake, median protein intake was $14.3 \%$ across a narrow range (interquartile range $13.3-$ $15 \cdot 2 \%)$. Dairy product and milk intake also did not vary widely (i.e. median of 1.6 servings of dairy products daily (interquartile range $0 \cdot 9-2 \cdot 6)$ ).

Calibrated protein intake, expressed in absolute terms, relative to calibrated energy intake, or relative to body weight, was not associated with free IGF, IGF-I or IGFBP-3 levels (Table 3). However, there was a positive association between free IGF-I levels and milk intake (Table 4). Specifically, a three-serving increase in milk intake per $\mathrm{d}$ was associated with an estimated average $18.6 \%$ increase in free IGF-I levels (95\% CI 0.9, 39.3\%) (Table 4).

IGFBP-3 levels were not associated with dairy product or milk intake in continuous or categorical analyses. Results obtained from logistic regression models between calibrated protein intake, dairy product intake and milk intake categorised into quartiles and the odds of high serum total IGF-I, free IGF-I and IGFBP-3 levels (defined as top 10\%) were consistent with those obtained from linear regression models (data not shown). The results of analyses that modelled the exposure variable as a categorical or continuous variable were similar, and there was no statistically significant or discernible difference in estimates restricted to (1) non-HT users and (2) women without prevalent diabetes. Nor were the results meaningfully affected by stratification by BMI category $(<25$, $25-29 \cdot 9$, and $\geq 30 \mathrm{~kg} / \mathrm{m}^{2}$ ), protein source (percentage of energy obtained from animal vegetable and milk protein) or milk fat content (whole/2\%, 1\% and skimmed) (all $P>0.05$ for interaction, data not shown). Analyses including

Table 2. Geometric mean levels and Spearman correlations between insulin-like growth factor (IGF) axis proteins (Geometric means and 95\% confidence intervals)

\begin{tabular}{|c|c|c|c|c|c|}
\hline IGF axis proteins $(\mathrm{ng} / \mathrm{ml})$ & Geometric mean & $95 \% \mathrm{Cl}$ & Free IGF & Total IGF & IGFBP-3 \\
\hline Free IGF-I & 0.30 & $0.28,0.32$ & & & \\
\hline Total IGF-I & $117 \cdot 4$ & $114 \cdot 0,120 \cdot 8$ & $0.23^{*}$ & & \\
\hline IGFBP-3 & 4041 & 3984,4100 & $0.14^{\star}$ & $0.46^{*}$ & \\
\hline
\end{tabular}

IGFBP, insulin-like growth factor-binding protein. ${ }^{\star} P<0.05$. 
Table 3. Multivariate linear regression associations between free insulin-like growth factor (IGF)-I, total IGF-I and insulin-like growth factor-binding protein (IGFBP)-3 levels and calibrated protein intake†‡

$(\beta$-Coefficients and $95 \%$ confidence intervals)

\begin{tabular}{|c|c|c|c|c|c|c|c|}
\hline & \multirow[b]{2}{*}{$n$} & \multicolumn{2}{|c|}{$\begin{array}{l}\text { Calibrated protein } \\
\text { (\% energy) }\end{array}$} & \multicolumn{2}{|c|}{$\begin{array}{l}\text { Calibrated protein } \\
(\mathrm{g} / \mathrm{d})\end{array}$} & \multicolumn{2}{|c|}{$\begin{array}{l}\text { Calibrated protein } \\
\left(\mathrm{g} / \mathrm{kg} \text { body weight per } \mathrm{d}^{\star}\right)\end{array}$} \\
\hline & & $\beta$ & $95 \% \mathrm{Cl}$ & $\beta$ & $95 \% \mathrm{Cl}$ & $\beta$ & $95 \% \mathrm{Cl}$ \\
\hline Free IGF (\%) & 732 & 0.02 & $-0.004,0.04$ & 0.003 & $-0.003,0.007$ & -0.02 & $-0.03,0.02$ \\
\hline Total IGF (\%) & 759 & -0.34 & $-3.94,1.75$ & -0.15 & $-0.91,0.43$ & $1 \cdot 9$ & $-2 \cdot 7,3 \cdot 0$ \\
\hline IGFBP-3 (\%) & 736 & $6 \cdot 81$ & $-43 \cdot 4,50 \cdot 8$ & $3 \cdot 11$ & $-10 \cdot 3,14 \cdot 4$ & $-7 \cdot 8$ & $-67 \cdot 6,33 \cdot 7$ \\
\hline
\end{tabular}

$\%$ energy, percentage of energy intake.

* Scaled to $0.1 \mathrm{~g} / \mathrm{kg}$ body weight per $\mathrm{d}$.

†Adjusted for age, BMI, race/ethnicity, education, biomarker-calibrated energy intake, alcohol intake, smoking, physical activity and hormone therapy use.

‡Primary exposure and outcome variables In-transformed to represent the expected percentage difference in IGF levels per percentage difference in protein intake.

uncalibrated energy and protein intake instead of calibrated one were also similar (data not shown). Lastly, we assessed whether the relationship of milk consumption with free IGF-I levels might be explained by $\mathrm{Ca}$ intake. There was no association between free IGF-I levels and $\mathrm{Ca}$ intake $(\beta=0,95 \% \mathrm{CI}$ $-0.002,0.0003)$ for $\mathrm{Ca}$ from foods alone as well as from supplements $(\beta=0,95 \% \mathrm{CI}-0 \cdot 001,0)$.

\section{Discussion}

The present study supports evidence from clinical trials and observational studies of a specific relationship between milk consumption and IGF-I levels, although in the present study this relationship was only statistically significant for free IGF-I levels. To our knowledge, this is the first study of the relationship between protein intake and milk consumption and free IGF-I levels. Our data, however, did not support reports from other epidemiological studies suggesting a positive relationship between higher overall total protein intake and higher total IGF-I levels ${ }^{(10-12,25)}$. Biomarker calibration of protein intake did not appreciably affect the results.

Prior observational studies ${ }^{(13,26-28)}$ also support a positive association between protein intake, particularly from dairy sources, and total IGF-I levels ${ }^{(10-12,25)}$. Data from the European Prospective Investigation into Cancer and Nutrition
(EPIC, $n 4731$ men and women) indicate 2.5 and $2.4 \%$ increases in IGF-I levels per 3 and $2 \%$ increase in energy derived from total protein and dairy protein, respectively ${ }^{(26)}$. Given that each serving of dairy products equates to $601 \mathrm{~kJ}^{(29)}$ and mean energy intake was $9876 \mathrm{~kJ}$ in the EPIC, $2 \%$ energy equates to $198 \mathrm{~kJ}$ or approximately $1 / 3$ dairy product serving. Assuming a linear dose response, this would equate to a $22.5 \%$ increase in IGF-I levels with a three-serving dairy product increase per $\mathrm{d}$, which is consistent with the strength of the association observed in the present study (17.3\%) and in clinical trials (range 8-52\%). Moreover, of the protein sources examined (plant, meat, dairy products, fish and eggs) in the EPIC, only dairy products were found to be significantly associated with IGF-I levels. The Nurses' Health Study, examining a comprehensive list of dietary correlates, has reported 9.3 and $7 \cdot 7 \%$ higher IGF-I levels by comparing highest $v$. lowest quintiles of total protein and dairy protein, respectively ${ }^{(13)}$. Similar to the present study, prior studies examining correlates of IGFBP-3 levels ${ }^{(15,26,27)}$ have reported no significant associations with either total dietary protein intake or dairy protein intake.

In prior clinical trials, an additional $20-30 \mathrm{~g}$ of protein, often whey protein, or two to three milk servings daily have been shown to result in increases in IGF-I levels of $8-10 \%$ that were sustained for up to 2 years ${ }^{(10-12,25)}$. This is well above

Table 4. Percent difference in insulin-like growth factor (IGF) levels per three-serving increase in daily dairy product and milk intake estimated from linear regression models $\dagger$ (Percent differences and 95\% confidence intervals)

\begin{tabular}{|c|c|c|c|c|}
\hline & \multicolumn{2}{|c|}{ Total dairy products } & \multicolumn{2}{|l|}{ Milk } \\
\hline & Percent difference & $95 \% \mathrm{Cl}$ & Percent difference & $95 \% \mathrm{Cl}$ \\
\hline Free IGF (\%) & $11 \cdot 0$ & $-1 \cdot 3,25 \cdot 3$ & $18 \cdot 6^{*}$ & $0.9,39.3$ \\
\hline Total IGF (\%) & $4 \cdot 7$ & $-0.8,10.5$ & 4.4 & $-3 \cdot 0,12 \cdot 3$ \\
\hline IGFBP-3 (\%) & 0.7 & $-2 \cdot 1,3.5$ & $-1 \cdot 1$ & $-4 \cdot 7,2 \cdot 7$ \\
\hline \multicolumn{5}{|c|}{$\begin{array}{l}\text { IGFBP-3, insulin-like growth factor-binding protein-3. } \\
\text { * } P<0.05 \text {. } \\
\text { † Estimated from In-transformed outcome and primary exposure variables in multivariate linear regression } \\
\text { models adjusted for age, BMI, race/ethnicity, education, energy intake, alcohol intake, smoking, physical } \\
\text { activity and hormone therapy use. Estimates were scaled (base }=2.58 \text { and } 4.3 \text { for dairy products } \\
\text { and milk, respectively) to reflect intervention amount of three servings (average dairy product intake is } \\
1.9 \text { servings per d, so a three-serving increase per d is equal to } 158 \% \text { increase, and average milk intake } \\
\text { is } 0.8 \text { servings per d, so a three-serving increase is equal to } 375 \% \text { increase). }\end{array}$} \\
\hline
\end{tabular}


typical average daily milk consumption of 0.7 servings for the US population aged 2 years and above (National Health and Nutrition Examination Survey (NHANES) 2003-8 data ${ }^{(29)}$. In the present study, mean daily milk consumption was 0.8 (SD 1.0) servings, less than $25 \%$ of women reported consuming three milk servings per $d$, and the upper limit of intake was $7 \cdot 2$ servings per $d$. Thus, the magnitude of the effect size observed in the present study is in keeping with that found in clinical trials and, for the first time, indicates that dairy product intake within the upper range of the typical American diet increases free IGF-I levels. Furthermore, a meta-analysis of eight randomised trials has reported a weighted mean difference of circulating IGF-I levels between milk intervention and control groups of $13.8 \mathrm{ng} / \mathrm{ml}$ (95\% CI $6 \cdot 1,21.5$ ), and postulated components of milk that may increase IGF-I levels include its nutrient composition of high protein, fat, and $\mathrm{Ca}$ and/or contaminants or hormones such as oestrogens and $\mathrm{IGF}^{(30)}$.

Collectively, the present study and prior reports are supportive of a particular association between IGF-I levels and milk consumption, which may involve components of milk other than protein. That is, the consistent positive association between IGF-I levels and milk consumption might be explained by a single non-protein nutrient that, nonetheless, may be correlated with total protein or milk protein (since these two factors were variably significant in some prior studies, but not in the present study or several others) or possibly a combination of milk components that include protein. For example, the Singapore Chinese Health Study has reported a positive association between $\mathrm{Ca}$ intake from foods and supplements with IGF-I and IGFBP-3 levels ${ }^{(31)}$. However, Ca intake, both from foods alone and in combination with $\mathrm{Ca}$ supplement use, was not significantly associated with free IGF-I, total IGF-I or IGFBP-3 levels in the present study.

The limitations of the present study should be considered while interpreting the data. Diet was characterised using a FFQ, which is limited by both differential and non-differential measurement errors ${ }^{(32)}$. For example, the participants were not queried about some items that could contribute to protein intake, such as protein supplements. However, using biomarkers of energy and protein intake, we were able to mitigate some important sources of measurement errors associated with energy and total protein intake ${ }^{(17)}$. Similar to representative samples of the US population ${ }^{(33)}$, the range of protein, and particularly dairy product and milk, intake was not wide in this population. Since the dairy, cheese and yogurt food group variables are a summary of several FFQ items having different weights and protein content, we could not compute with certainty the protein intake for dairy, cheese and yogurt groups. However, our analyses of IGF axis protein levels and their relationship with protein consumption were null even when examined separately by source (animal, vegetable or milk protein), suggesting that protein consumption alone is not responsible for the observed positive association between milk consumption and free IGF-I levels.

In conclusion, the study data suggest that a three-serving increase in milk consumption per $d$ is associated with an
18.6\% (95\% CI 0.9, 39.3\%) increase in free IGF-I levels. These data provide new insight into the factors that influence free IGF-I, presumably the most bioactive component of IGF-I, a hormone peptide that is the primary mediator of the effects of growth hormone and has been reported to be associated with several major health conditions, including diabetes, CVD and cognitive function in the elderly.

\section{Acknowledgements}

The WHI programme is funded by the National Heart, Lung, and Blood Institute, National Institutes of Health, US Department of Health and Human Services, through contracts N01WH22110, 24152, 32100-2, 32105-6, 32108-9, 32111-13, 32115, 32118-32119, 32122, 42107-26, 42129-32 and 44221. This work was also supported by PO1 CA53996. Dr Beasley's involvement was supported by R00AG035002 by the National Institute of Aging, Dr Strickler's involvement was supported by R01DK080792, and Dr Prentice's involvement was supported by R01CA119171 and P01CA53996. None of the funding sources had a role in the design and analysis of the study or in the writing of this article.

The authors' contributions are as follows: J. M. B. analysed the data and drafted the initial manuscript; M. J. G., R. L. P. and H. D. S. were responsible for the study design and implementation and contributed substantively to the writing of the manuscript; M. L. N., L. F. T., M. Z. V. and A. Z. L. reviewed and edited the manuscript.

None of the authors has any conflicts of interest to declare.

\section{References}

1. Houston DK, Nicklas BJ, Ding J, et al. (2008) Dietary protein intake is associated with lean mass change in older, community-dwelling adults: the Health, Aging, and Body Composition (Health ABC) Study. Am J Clin Nutr 87, 150-155.

2. Beasley JM, LaCroix AZ, Neuhouser ML, et al. (2010) Protein intake and incident frailty in the Women's Health Initiative observational study. J Am Geriatr Soc 58, 1063-1071.

3. Froesch ER, Schmid C, Schwander J, et al. (1985) Actions of insulin-like growth factors. Annu Rev Physiol 47, 443-467.

4. Yu H \& Rohan T (2000) Role of the insulin-like growth factor family in cancer development and progression. J Natl Cancer Inst 92, 1472-1489.

5. Rajpathak SN, Gunter MJ, Wylie-Rosett J, et al. (2009) The role of insulin-like growth factor-I and its binding proteins in glucose homeostasis and type 2 diabetes. Diabetes Metab Res Rev 25, 3-12.

6. Zapf J, Schmid C \& Froesch ER (1984) Biological and immunological properties of insulin-like growth factors (IGF) I and II. Clin Endocrinol Metab 13, 3-30.

7. Kawai M \& Rosen CJ (2010) The IGF-I regulatory system and its impact on skeletal and energy homeostasis. J Cell Biochem 111, 14-19.

8. Juul A, Holm K, Kastrup KW, et al. (1997) Free insulin-like growth factor I serum levels in 1430 healthy children and adults, and its diagnostic value in patients suspected of growth hormone deficiency. J Clin Endocrinol Metab 82, 2497-2502.

9. Thissen JP, Ketelslegers JM \& Underwood LE (1994) Nutritional regulation of the insulin-like growth factors. Endocr Rev 15, 80-101. 
10. Schurch MA, Rizzoli R, Slosman D, et al. (1998) Protein supplements increase serum insulin-like growth factor-I levels and attenuate proximal femur bone loss in patients with recent hip fracture. A randomized, double-blind, placebocontrolled trial. Ann Intern Med 128, 801-809.

11. Zhu K, Meng X, Kerr DA, et al. (2011) The effects of a two-year randomized, controlled trial of whey protein supplementation on bone structure, IGF-1, and urinary calcium excretion in older postmenopausal women. J Bone Miner Res 26, 2298-2306.

12. Heaney RP, McCarron DA, Dawson-Hughes B, et al. (1999) Dietary changes favorably affect bone remodeling in older adults. J Am Diet Assoc 99, 1228-1233.

13. Holmes MD, Pollak MN, Willett WC, et al. (2002) Dietary correlates of plasma insulin-like growth factor I and insulin-like growth factor binding protein 3 concentrations. Cancer Epidemiol Biomarkers Prev 11, 852-861.

14. Ma J, Giovannucci E, Pollak M, et al. (2001) Milk intake, circulating levels of insulin-like growth factor-I, and risk of colorectal cancer in men. J Natl Cancer Inst 93, 1330-1336.

15. Kaklamani VG, Linos A, Kaklamani E, et al. (1999) Dietary fat and carbohydrates are independently associated with circulating insulin-like growth factor 1 and insulin-like growth factor-binding protein 3 concentrations in healthy adults. J Clin Oncol 17, 3291-3298.

16. Prentice RL, Mossavar-Rahmani Y, Huang Y, et al. (2011) Evaluation and comparison of food records, recalls, and frequencies for energy and protein assessment by using recovery biomarkers. Am J Epidemiol 174, 591-603.

17. Neuhouser ML, Tinker L, Shaw PA, et al. (2008) Use of recovery biomarkers to calibrate nutrient consumption self-reports in the Women's Health Initiative. Am J Epidemiol 167, 1247-1259.

18. The Women's Health Initiative Study Group (1998) Design of the Women's Health Initiative clinical trial and observational study. The Women's Health Initiative Study Group. Control Clin Trials 19, 61-109.

19. Gunter MJ, Hoover DR, Yu H, et al. (2008) A prospective evaluation of insulin and insulin-like growth factor-I as risk factors for endometrial cancer. Cancer Epidemiol Biomarkers Prev 17, 921-929.

20. Gunter MJ, Hoover DR, Yu H, et al. (2008) Insulin, insulin-like growth factor-I, endogenous estradiol, and risk of colorectal cancer in postmenopausal women. Cancer Res 68, 329-337.

21. Gunter MJ, Hoover DR, Yu H, et al. (2009) Insulin, insulinlike growth factor-I, and risk of breast cancer in postmenopausal women. J Natl Cancer Inst 101, 48-60.
22. Patterson RE, Kristal AR, Tinker LF, et al. (1999) Measurement characteristics of the Women's Health Initiative food frequency questionnaire. Ann Epidemiol 9, 178-187.

23. Food and Nutrition Board, Institute of Medicine of the National Academies (2005) Dietary Reference Intakes for Energy, Carbohydrate, Fiber, Fat, Fatty Acids, Cholesterol, Protein, and Amino Acids (Macronutrients). Washington, DC: National Academies Press.

24. Harrell FE (1991) Regression Modeling Strategies. New York, NY: Springer.

25. Hoppe C, Kristensen M, Boiesen M, et al. (2009) Short-term effects of replacing milk with cola beverages on insulin-like growth factor-I and insulin-glucose metabolism: a $10 \mathrm{~d}$ interventional study in young men. Br J Nutr 102, 1047-1051.

26. Crowe FL, Key TJ, Allen NE, et al. (2009) The association between diet and serum concentrations of IGF-I, IGFBP-1, IGFBP-2, and IGFBP-3 in the European Prospective Investigation into Cancer and Nutrition. Cancer Epidemiol Biomarkers Prev 18, 1333-1340.

27. Vrieling A, Voskuil DW, Bueno de Mesquita HB, et al. (2004) Dietary determinants of circulating insulin-like growth factor (IGF)-I and IGF binding proteins $1,-2$ and -3 in women in the Netherlands. Cancer Causes Control 15, 787-796.

28. Norat T, Dossus L, Rinaldi S, et al. (2007) Diet, serum insulinlike growth factor-I and IGF-binding protein-3 in European women. Eur J Clin Nutr 61, 91-98.

29. Fulgoni VL 3rd, Keast DR, Auestad N, et al. (2011) Nutrients from dairy foods are difficult to replace in diets of Americans: food pattern modeling and an analyses of the National Health and Nutrition Examination Survey 2003-2006. Nutr Res 31, 759-765.

30. Qin LQ, He K \& Xu JY (2009) Milk consumption and circulating insulin-like growth factor-I level: a systematic literature review. Int J Food Sci Nutr 60, Suppl. 7, 330-340.

31. Probst-Hensch NM, Wang H, Goh VH, et al. (2003) Determinants of circulating insulin-like growth factor I and insulinlike growth factor binding protein 3 concentrations in a cohort of Singapore men and women. Cancer Epidemiol Biomarkers Prev 12, 739-746.

32. Subar AF, Kipnis V, Troiano RP, et al. (2003) Using intake biomarkers to evaluate the extent of dietary misreporting in a large sample of adults: the OPEN study. Am J Epidemiol 158, $1-13$.

33. Fulgoni VL 3rd (2008) Current protein intake in America: analysis of the National Health and Nutrition Examination Survey, 2003-2004. Am J Clin Nutr 87, 1554S-1557S. 